\title{
Hydrochar-derived adsorbent for the removal of diclofenac from aqueous solution
}

\author{
Velma Beri Kimbi Yaah ${ }^{1} \cdot$ Mohamed Zbair $^{2} \cdot$ Sérgio Botelho de Oliveira $^{3} \cdot$ Satu Ojala $^{1}$ (1)
}

Received: 2 October 2020 / Accepted: 5 December 2020

(c) The Author(s) 2021

\begin{abstract}
The characteristics and diclofenac adsorption properties of a carbon adsorbent prepared from palm kernel shells were studied. The adsorbent prepared via hydrothermal carbonization followed by an activation in nitrogen flow had a mesoporous structure with homogenous pore distribution and the specific surface area of $131 \mathrm{~m}^{2} \mathrm{~g}^{-1}$. The Raman spectra showed a formation of graphene or graphite structures in the material during activation with small number of defects based on its $\mathrm{I}_{\mathrm{D}} / \mathrm{I}_{\mathrm{G}}$ ratio of about 0.5 . The FTIR analysis showed both a qualitative and quantitative decrease in the functional groups of the raw material after activation. The developed adsorbent was found to be effective in the removal of diclofenac with $95 \%$ maximum removal at $\mathrm{pH} 2$, adsorbent dose of $15 \mathrm{gL}^{-1}$ and adsorbate dose of $50 \mathrm{mgL}^{-1}$. Diclofenac adsorption followed the Langmuir isotherm model with correlation coefficient $\mathrm{R}^{2}>0.98$. The adsorption kinetics was explained by the second-order kinetic model with rate constant $\left(\mathrm{K}_{2}\right) 0.869 \mathrm{~min}^{-1}$. The interaction via aromatic $\pi-\pi$ stacking and hydrogen bonding between $-\mathrm{OH}$ groups of phenol and carboxylic acid groups of DCF are leading to a good adsorption efficiency despite of the low surface area of the adsorbent.
\end{abstract}

Graphic abstract

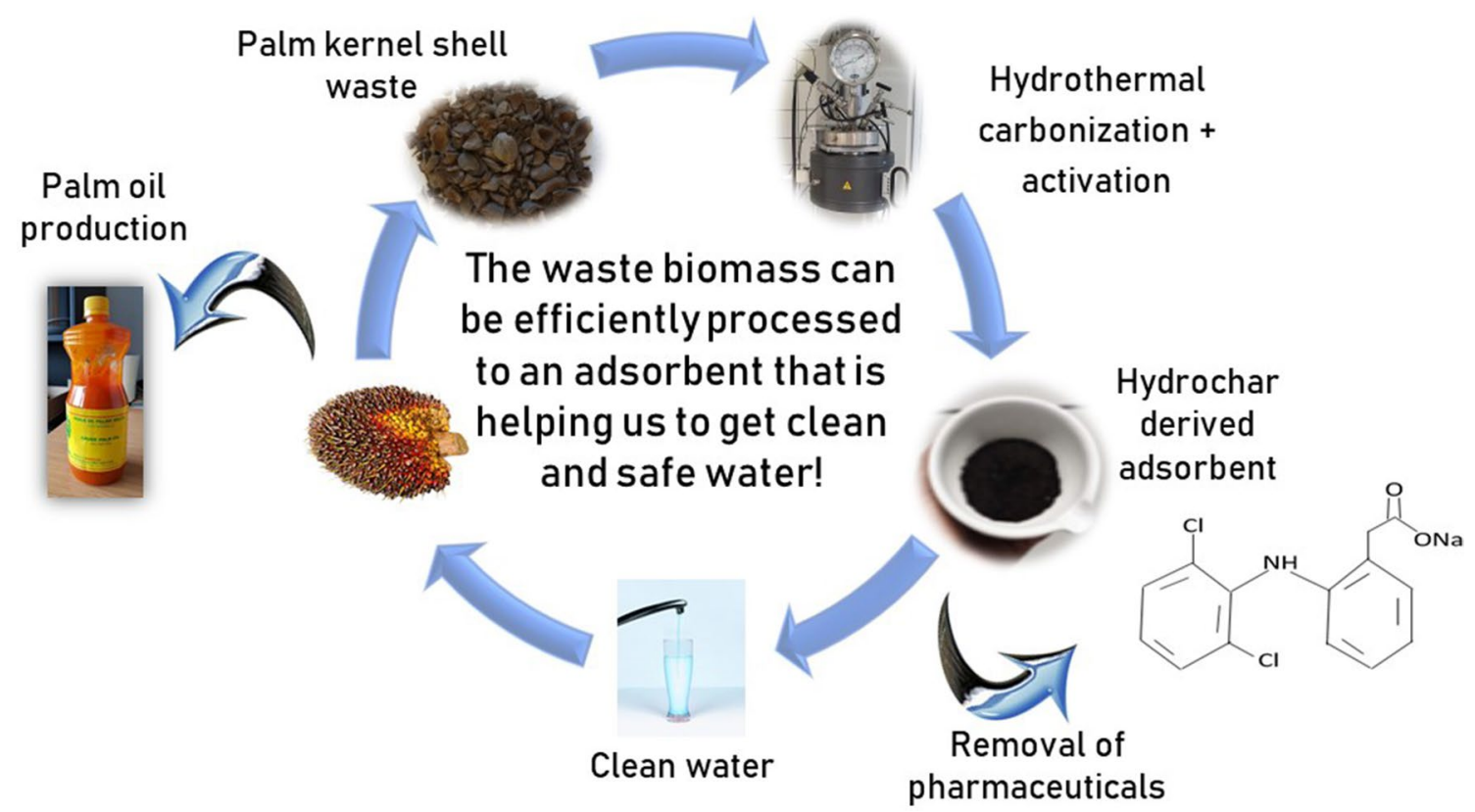

Keywords Water purification · Anti-inflammatory drug $\cdot$ Palm kernel shells $\cdot$ Emerging pollutants $\cdot$ Hydrothermal carbonization

Extended author information available on the last page of the article 


\section{Introduction}

Hydrothermal carbonization (HTC) is a thermochemical conversion method carried out in conditions of subcritical water, where the material is heated in a closed environment under autogenous pressure [1]. HTC has been reported to be more energy efficient and economical compared to the other thermochemical conversion processes, such as pyrolysis. HTC has no specific requirements for pressure, and the pressure is dependent on the temperature used in the process. Water is used as a solvent, and thus wet feedstock can be utilized, which saves energy that is normally used to dry the feedstock before processing [2-5]. The solid product from HTC is called as hydrochar and its properties depend on the biomass source and the reaction conditions used [6, 7]. Generally, hydrochar is non-toxic and hydrophobic. The surface chemistry, porosity, particle size and specific surface area of hydrochar are dependent on the temperature and reaction time used in HTC. Corn stove hydrochars produced at $250{ }^{\circ} \mathrm{C}$ for $4 \mathrm{~h}$, and pinewood at $300{ }^{\circ} \mathrm{C}$ for $20 \mathrm{~min}$, had specific surfaces areas of $4 \mathrm{~m}^{2} \mathrm{~g}^{-1}$ and $21 \mathrm{~m}^{2} \mathrm{~g}^{-1}$, respectively. The specific surface area of the hydrochar can be increased using activation. In principal, there are two types of activation-physical and chemical. Physical activation is usually carried out at higher temperatures, even greater than $900{ }^{\circ} \mathrm{C}$, in a flow of steam, $\mathrm{CO}_{2}$ or both, while in chemical activation, activating agents like $\mathrm{KOH}$ are used at room or elevated temperatures $\left(600^{\circ} \mathrm{C}-800{ }^{\circ} \mathrm{C}\right)$. Chemical activation typically leads to high specific surface areas. For example, cellulose, rye straw and glucose hydrochar-derived adsorbents produced at $240{ }^{\circ} \mathrm{C}$ reached specific surface areas of 2250,2200 and $2219 \mathrm{~m}^{2} \mathrm{~g}^{-1}$, respectively, when using $\mathrm{KOH}$ as an activation chemical. Though chemical activation is faster and occurs at lower temperatures, it causes secondary pollution, and hence physical activation is more recommended [8-13]. The hydrochar surface contains typically number of oxygen-containing functional groups that have good adsorption affinity for both polar and non-polar functional groups leading to high adsorption capacity. This property might be lost from the hydrochar during the gas-phase activation intended to increase the specific surface area. Therefore, careful selection of the processing conditions is necessary.

Oil palm (Elaeis guineensis) is a major source of vegetable oil that is extracted from its flesh and shell. Oil palms are cultivated in South East Asia (Malaysia, Indonesia, and Thailand), Africa and several southern provinces of China. Malaysia produces about two million tons dry weight of oil palm shells annually, which are normally used as biofuels and building materials [14]. Previous research has been carried out on the use of palm shell activated carbon for adsorption of pollutants, such as heavy metals (lead, copper and nickel ions), phenol and dyes (methylene blue), in aqueous solutions [15-18]. However, less information is available related to the use of adsorbents derived from palm kernel shells in adsorption of emerging pollutants and using HTC as the primary preparation method.

There has been an increase in the level of micro-pollutants especially pharmaceuticals in the effluents of wastewater treatment plants, in sewage water, groundwater and drinking water supplies. Only about $30 \%$ of pharmaceuticals are absorbed in the human body with the rest being sent out in urine and faeces. Diclofenac is a non-steroidal anti-inflammatory drug used worldwide as analgesic, antiarthritic compounds and for the remediation of menstrual pain of females [19-23]. It has a low solubility in water and due to its negative charge, it can easily escape from the nanofiltration unit of the water treatment plant. It is already known that its presence in the aquatic ecosystem can cause damage to fish tissue and change its biochemical functions $[24,25]$. Therefore, finding an efficient technology for the removal of diclofenac from water is very important.

The objective of this work was to develop a new, efficient and economic adsorbent for the removal of diclofenac in water by using hydrothermal carbonization as the primary processing technology. Palm kernel shells were selected as the raw materials. To explain the performance of the developed adsorbent, its chemical and structural properties were characterized. The adsorption isotherms and kinetics of adsorption were evaluated to get more information on the adsorption process.

\section{Materials and Methods}

\section{Materials}

Palm kernel shells were collected from the North and South-West regions of Cameroon. The shells were washed to remove the fibres and sun dried at temperature of about $32{ }^{\circ} \mathrm{C}$. After drying, the shells were ground and sieved to a particle size of $<84 \mathrm{~mm}$.

\section{Chemical reagents}

All the chemicals used in this research were of analytical reagent grade. Diclofenac sodium salt with a molecular weight of $318.13 \mathrm{~g} \mathrm{~mol}^{-1}$ purchased from Sigma Aldrich, 99.5\% sodium chloride and $37 \%$ hydrochloric acid from Alphatec, sodium hydroxide from Neon Commercial Ltda and 95\% ethanol from Química Contemporânea Ltda were used as reagents. Diclofenac sodium salt (Fig. 1a) is typically used in pharmaceuticals since diclofenac is fat-soluble and does not easily dissolve in water. Deionized water was 

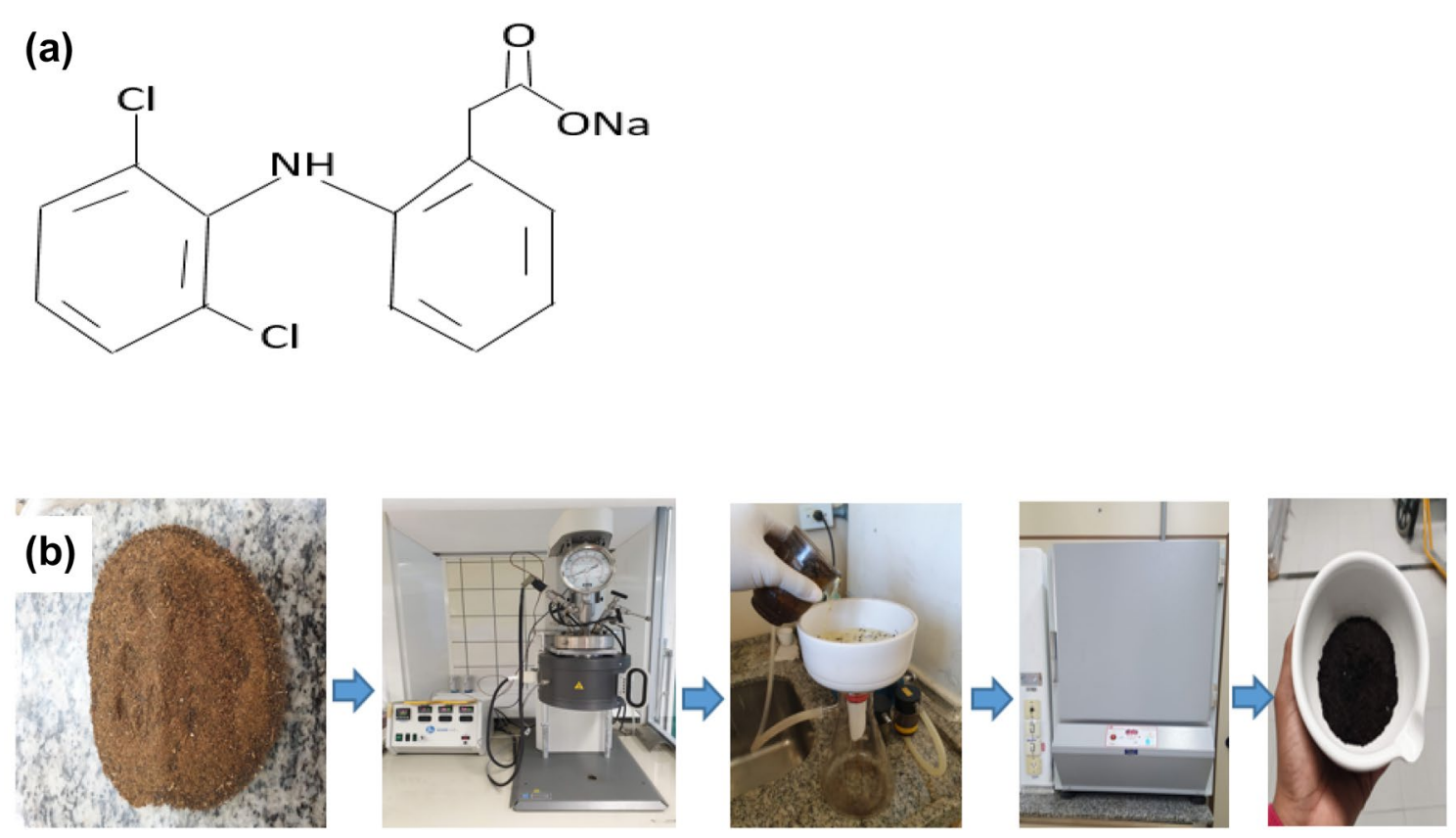

Fig. 1 a Chemical structure of diclofenac sodium, b Schematics for hydrothermal carbonization of palm kernel shells

used for the preparation of all model water solutions and as the solvent for hydrothermal carbonization.

\section{Hydrothermal carbonization of Palm kernel shells}

Hydrothermal carbonization (Fig. 1b) of palm kernel shells was done in a high-pressure Parr reactor. The reaction conditions were optimized in our earlier work and are reported in [26]. The ratio of palm kernel shells to deionized water used was 1:5. The mixture of palm kernel shells and deionized water was put in a Teflon cup with a $30 \%$ air space. The reactor was heated to $200{ }^{\circ} \mathrm{C}$ for $4 \mathrm{~h}$ with a heating rate of $40{ }^{\circ} \mathrm{C} \mathrm{min}^{-1}$. The reactor was then left to cool down, and the solid phase (hydrochar) was filtered out and dried at $80{ }^{\circ} \mathrm{C}$ for $12 \mathrm{~h}$. Activation of the hydrochar was done in a nitrogen flow of $60 \mathrm{~mL} \min ^{-1}$ at $400{ }^{\circ} \mathrm{C}$ for $4 \mathrm{~h}$.

\section{Characterization}

To determine the specific surface area and pore structure of the materials, nitrogen physisorption analysis (Micromeritics ASAP 2020) at $-195{ }^{\circ} \mathrm{C}$ was carried out using the BET-BJH and Horvath-Kawazoe methods. The material was evacuated for $30 \mathrm{~min}$ at $200{ }^{\circ} \mathrm{C}$ before analysis. The morphology and structure of the palm kernel shell, hydrochar and hydrochar-derived adsorbent were analysed using a scanning electron microscopy (SEM; Jeol JSM-IT300) operated in vacuum, with electron acceleration voltage of $15 \mathrm{kV}$ in backscattered electron mode. The elemental analyses were performed using the energy-dispersion spectroscopy
(EDS) technique, with Oxford Instruments X-Max N X-ray detector attached to the microscope. The Fourier transform infrared spectrometer (FTIR) (Perkin Elmer Spectrum 400) with attenuated total reflectance (ATR) accessory was used to study the functional groups on the adsorbents before and after adsorption experiments. The change in mass with temperature was analysed using thermogravimetric analysis TGA-DTG (Shimadzu DTG-60H) to evaluate the thermal stability of the hydrochar. For the analysis, the sample was placed in a $70 \mu \mathrm{L}$ platinum crucible and heated from $25^{\circ} \mathrm{C}$ to $700{ }^{\circ} \mathrm{C}$ with a heating rate of $10{ }^{\circ} \mathrm{C} \mathrm{min}^{-1}$ under nitrogen flow of $100 \mathrm{~mL} \mathrm{~min}^{-1}$. Raman spectra of the materials were obtained using the time-gated Pico Raman spectrometer $(532 \mathrm{~nm}$ pulsed laser with a shot length of $150 \mathrm{ps}$ and frequency of 40-100 kHz) from Timegate Instruments Ltd. Measurements were done in a wave number range of $100 \mathrm{~cm}^{-1}-2100 \mathrm{~cm}^{-1}$, and the wet samples were rotated during the measurements. XRD analysis of the hydrocharderived adsorbent was realized using Rikagu SmartLab XRD device using $9 \mathrm{~kW}$ rotating $\mathrm{Cu}$ anode $\mathrm{X}$-ray generator. The scanning was done at $2 \theta$ range $5-130^{\circ}$ using a step size of $0.02^{\circ}$.

\section{Adsorption experiments}

Batch adsorption studies were done at several concentrations of diclofenac sodium, dosages of adsorbent, temperatures, and contact times. Each experiment was carried out in a $250 \mathrm{~mL}$ Erlenmeyer flask containing $100 \mathrm{~mL}$ volume of diclofenac solution at $\mathrm{pH} 2$. The mixtures were shaken on a 
SI-300R thermostat incubator shaker (Nova Analitica Imp. Exp. Ltda) at $200 \mathrm{rpm}$. Liquid samples were collected at 10, 15 and 30 min intervals, and the concentration of Diclofenac (DCF) was analysed using a UV Vis spectrometer (UV-M51) at the maximum absorbance wavelength of $276 \mathrm{~nm}$. The removal percentage of diclofenac at a given time t was calculated using the Eq. 1. Equations 2 and 3 were used to calculate the amount of diclofenac adsorbed per mass unit $\left(\mathrm{mg} \mathrm{g}^{-1}\right)$ of adsorbent at any given time and at equilibrium.

$\operatorname{Removal}(\%)=\frac{(\mathrm{Co}-\mathrm{Ct}) 100}{\mathrm{Co}}$

$\mathrm{Qt}=\frac{(\mathrm{Co}-\mathrm{Ct}) \mathrm{V}}{\mathrm{m}}$

$\mathrm{Qe}=\frac{(\mathrm{Co}-\mathrm{Ce}) \mathrm{V}}{\mathrm{m}}$

In the equations, $\mathrm{Co}$ is initial concentration of diclofenac sodium (DCF), $\mathrm{Ct}$ is DCF concentration at given time, $\mathrm{m}$ is mass of adsorbent, Ce is equilibrium DCF concentration and $\mathrm{V}$ is volume of solution (L).

Langmuir (Eq. 4) [27] and Freundlich (Eq. 5) [28] models were used in examining the equilibrium data and to find out information on distribution of DCF molecules at the solid-liquid interface.

$1 / Q_{e}=1 / Q_{\max }+1 /\left(K_{L} Q_{m} C_{e}\right)$

$\operatorname{Ln}\left(Q_{e}\right)=\ln K_{F}+1 / n \operatorname{Ln}\left(C_{e}\right)$

In the equations, $C_{e}$ is concentration at equilibrium, $Q_{e}$ is adsorption at equilibrium, $\mathrm{Q}_{\max }$ is maximum adsorption capacity and $\mathrm{K}_{\mathrm{L}}$ is Langmuir constant related to the affinity of adsorption sites for diclofenac $\left(\mathrm{Lmg}^{-1}\right), \mathrm{K}_{\mathrm{F}}$ is Freundlich constant, which is roughly an indicator for the sorption capacity $\left(\mathrm{mgg}^{-1}\right) /\left(\mathrm{mgL}^{-1}\right) 1 / \mathrm{n}$ and $\mathrm{n}$ is (dimensionless)
Freundlich constant indicative of the sorption intensity and heterogeneity.

Pseudo-first-order (PFO; Equation) [29] and pseudosecond-order (PSO; Eq. 7) [30] models were used in order to investigate the kinetics of the interaction between DCF and hydrochar-derived adsorbent (PKC) at the solid-liquid interface. The equations are described as:

$\operatorname{Ln}\left(Q_{e}-Q_{t}\right)=\log \left(Q_{e}\right)-K_{1} t / 2.303$

and

$t / Q_{t}=1 /\left(K_{2} Q_{t}^{2}\right)+1 / Q_{e}$

where $Q_{t}$ is adsorbed amount of diclofenac at time $t$, Qe is adsorption at equilibrium, $\mathrm{K}_{1}$ and $\mathrm{K}_{2}$ are rate constants.

\section{Regeneration experiments}

To study the reusability of the hydrochar-derived adsorbent, regeneration experiments were carried out in the following way: $1.5 \mathrm{~g}$ of the used material was put in $20 \mathrm{~mL}$ of $95 \%$ ethanol solution and shaken at $200 \mathrm{rpm}$ for $4 \mathrm{~h}$. After this, the adsorbent was filtered out, washed with distilled water and dried at $80{ }^{\circ} \mathrm{C}$ for $12 \mathrm{~h}$. The same adsorbent was used in diclofenac adsorption and regenerated for five times.

\section{Results and discussion}

\section{Characterization}

Figure 2 shows the SEM micrographs of the dried palm kernel shells (PKS), hydrochar (PKH) and hydrocharderived adsorbent $(\mathrm{PKC})$ at $2000 \times$ magnification. It can be observed that pores are homogenously distributed on the surface of the dried palm kernel shells. After hydrothermal carbonization, the pores are widened. During HTC process, water density and viscosity are decreased due to the

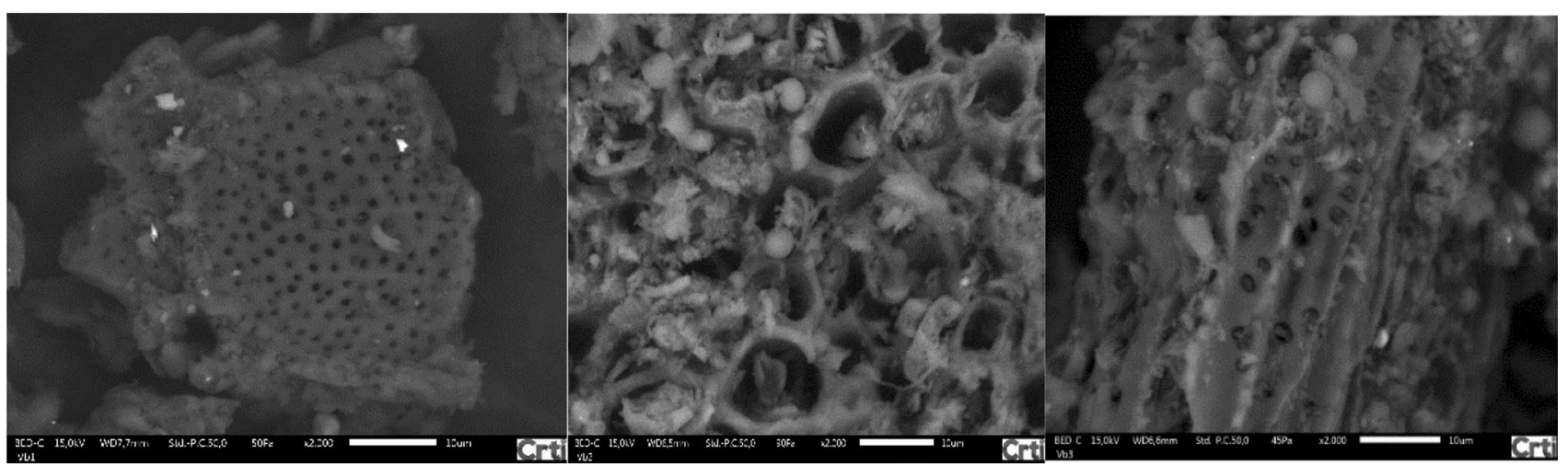

Fig. 2 SEM images for PKS, PKH and PKC at $2000 \times$ magnification 
subcritical conditions, and this is enhancing the removal of the inorganic material from the structure of the biomass while widening the pores [31]. During activation, volatile compounds are removed from the hydrochar leading to the appearance of the smaller pores [32]. This is visible in the images as well.

Based on $\mathrm{N}_{2}$ adsorption analysis, PKC was found to be predominantly mesoporous material with specific surface area of about $131 \mathrm{~m}^{2} \mathrm{~g}^{-1}$ and the diameter of pores between 2 and $50 \mathrm{~nm}$. The Horvath-Kawazoe plot showed the presence of some micropores as well. PKC had a total pore volume of $0.06 \mathrm{~cm}^{3} \mathrm{~g}^{-1}$. The specific surface area of PKH was found to be about $22 \mathrm{~m}^{2} \mathrm{~g}^{-1}$ with presence of mesopores between diameters of $15 \mathrm{~nm}$ and $20 \mathrm{~nm}$ and macropores with diameter greater than $50 \mathrm{~nm}$. The total pore volume of PKH was $0.1 \mathrm{~cm}^{3} \mathrm{~g}^{-1}$. This result showed that a significant increase in specific surface area and modification of porous structure appears during activation.

The thermogram for the palm kernel shells shown in Fig. 3a indicates a mass loss corresponding to about $13 \%$ up to temperature of $310^{\circ} \mathrm{C}$, which is related to the loss of adsorbed water and volatile compounds. This is an endothermic process, shown by an endothermic peak observed in the DTA curve. The exothermic feature between $320{ }^{\circ} \mathrm{C}$ and $420{ }^{\circ} \mathrm{C}$ is related to a mass loss of about $24 \%$. At this temperature range, decomposition of the functional groups with lower stability and decomposition of cellulose and hemicellulose takes place. In the temperature range between $420{ }^{\circ} \mathrm{C}$ and $700{ }^{\circ} \mathrm{C}$, there is a mass loss of about $38 \%$ and an exothermic peak centred at around $440{ }^{\circ} \mathrm{C}$, which is related to the decomposition of lignin [33]. This result is in accordance with the FTIR analysis where a disappearance of $\mathrm{C}=\mathrm{O}$ and $\mathrm{C}-\mathrm{O}$ groups after activation of the hydrochar is observed (Fig. 3b).

The FTIR spectra of the dried palm kernel shells (PKS), palm kernel shell hydrochar (PKH), hydrochar-derived adsorbent (PKC) and the adsorbent after diclofenac adsorption (PKA) are presented in Fig. 3b. All the materials displayed bands between $3300 \mathrm{~cm}^{-1}$ and $3700 \mathrm{~cm}^{-1}$ that correspond to $-\mathrm{OH}$ stretching vibration [34]. The intensity of the -OH bands in untreated palm kernel shells (PKS) is lower and broader than in the case of hydrochar (PKH). The higher intensity in the latter could originate from water used in the HTC process. The $\mathrm{C}=\mathrm{C}$ stretching vibrations of lignin aromatic rings around $1636 \mathrm{~cm}^{-1}$ and the aliphatic $\mathrm{C}-\mathrm{H}$ stretching vibrations between $2923 \mathrm{~cm}^{-1}$ and $2852 \mathrm{~cm}^{-1}$ are equally observed in all the materials [35].

One can observe bands at around $1450 \mathrm{~cm}^{-1}$ in the spectra of PKS and PKH corresponding to the $\mathrm{C}-\mathrm{H}$ deformation of lignin molecule typical for hydrochars and raw lignocellulosic materials [36]. The $\mathrm{C}=\mathrm{O}$ and $\mathrm{C}-\mathrm{O}$ stretching vibrations typical for saturated aliphatic compounds are present only in the PKS and PKH spectra. These groups are unstable under high temperature, which can explain the absence of these bands in the hydrochar-derived adsorbent (PKC) and PKA (after diclofenac adsorption) spectra. We also observe the $\mathrm{C}-\mathrm{O}$ stretching vibration between $1240 \mathrm{~cm}^{-1}$ and $1230 \mathrm{~cm}^{-1}$ in PKS and PKH. The absence of $\mathrm{C}-\mathrm{O}$ and $\mathrm{C}=\mathrm{O}$ groups in $\mathrm{PKC}$ is also an indication of the decomposition of hemicellulose and cellulose during activation [32, 37]. In general, the activation under $\mathrm{N}_{2}$ flow decreases the number of functional groups in the material both quantitatively and qualitatively. These functional groups play an important role in the adsorption of diclofenac on the adsorbent PKC. In the (a)

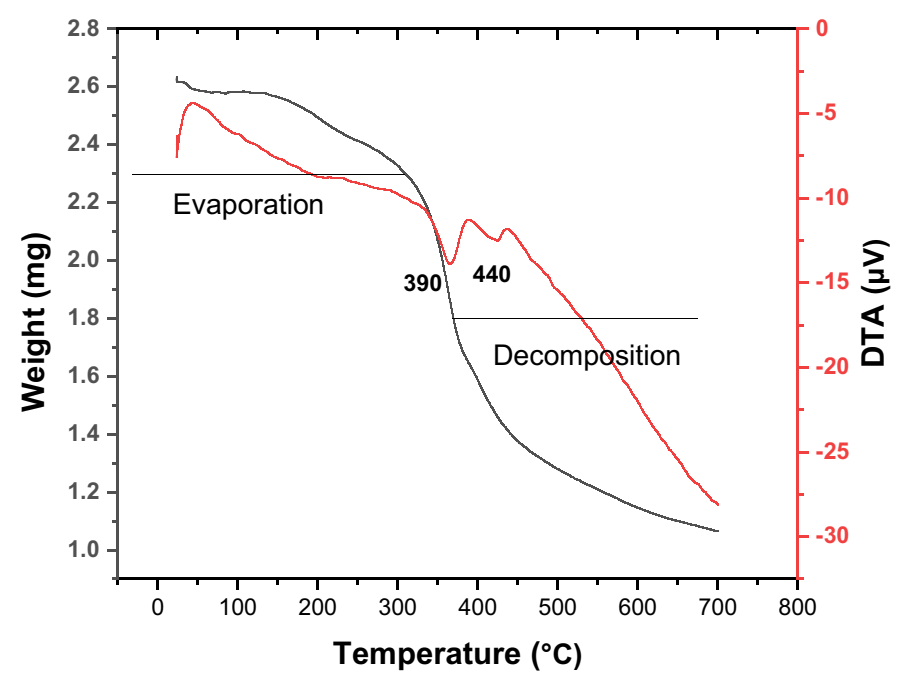

(b)

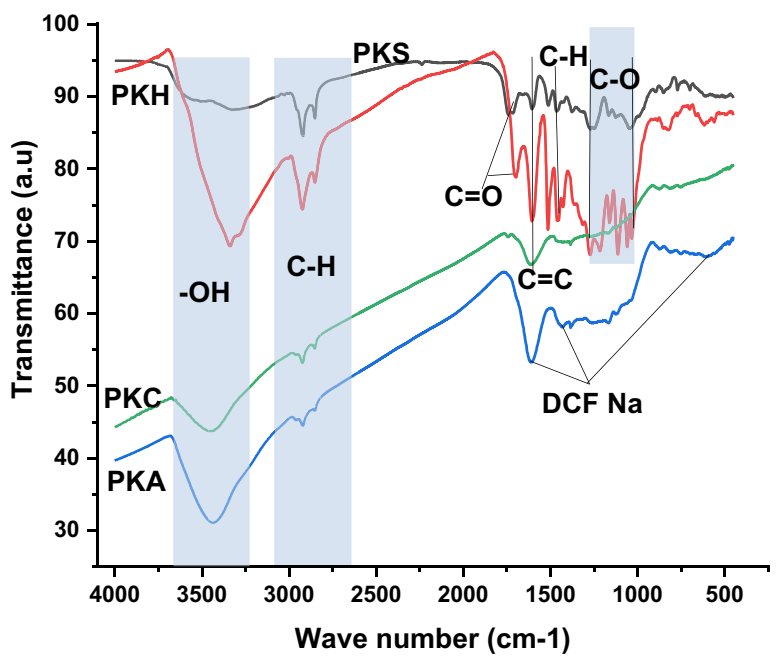

Fig. 3 a TGA/DTA results for the palm kernel shells, and (b) FTIR spectra of palm kernel shells (PKS), hydrochar (PKH), hydrochar-derived adsorbent (PKC) and after diclofenac adsorption (PKA) 
PKA sample, one can observe bands at around $747 \mathrm{~cm}^{-1}$, $1402 \mathrm{~cm}^{-1}, 1454 \mathrm{~cm}^{-1}$ and $1617 \mathrm{~cm}^{-1}$ all corresponding to diclofenac [38]. This proofs that diclofenac is adsorbed on the material.

The Raman spectra (Fig. 4) of the dried palm shells, hydrochar and hydrochar-derived adsorbent were used to evaluate the formation of graphite or graphene structures in the materials. Activation clearly changes the structure of the studied material. The Raman spectra show the development of $\mathrm{D}\left(1350 \mathrm{~cm}^{-1}\right)$ and $\mathrm{G}\left(1597 \mathrm{~cm}^{-1}\right)$ bands along with the activation. The $\mathrm{D}$ band shows the presence of defects or disorder in the graphite structure that may be beneficial for the material, while the $\mathrm{G}$ band is assigned to the symmetric stretching of the $\mathrm{sp}^{2}$ graphitic carbon $[39,40]$. The HTC treatment already seems to create some graphite or graphene structures to the material shown by $\mathrm{G}$ band. After activation, these two bands appear clearly for the $\mathrm{PKC}\left(\mathrm{I}_{\mathrm{D}} / \mathrm{I}_{\mathrm{G}}\right.$ ratio of about 0.5 ), while other spectral features remain less intense. The $\mathrm{I}_{\mathrm{D}} / \mathrm{I}_{\mathrm{G}}$ ratio of about 0.5 indicates a low amount of defects in the adsorbent. The Raman peaks below $1000 \mathrm{~cm}^{-1}$ are also changed during the activation. The intensities of these

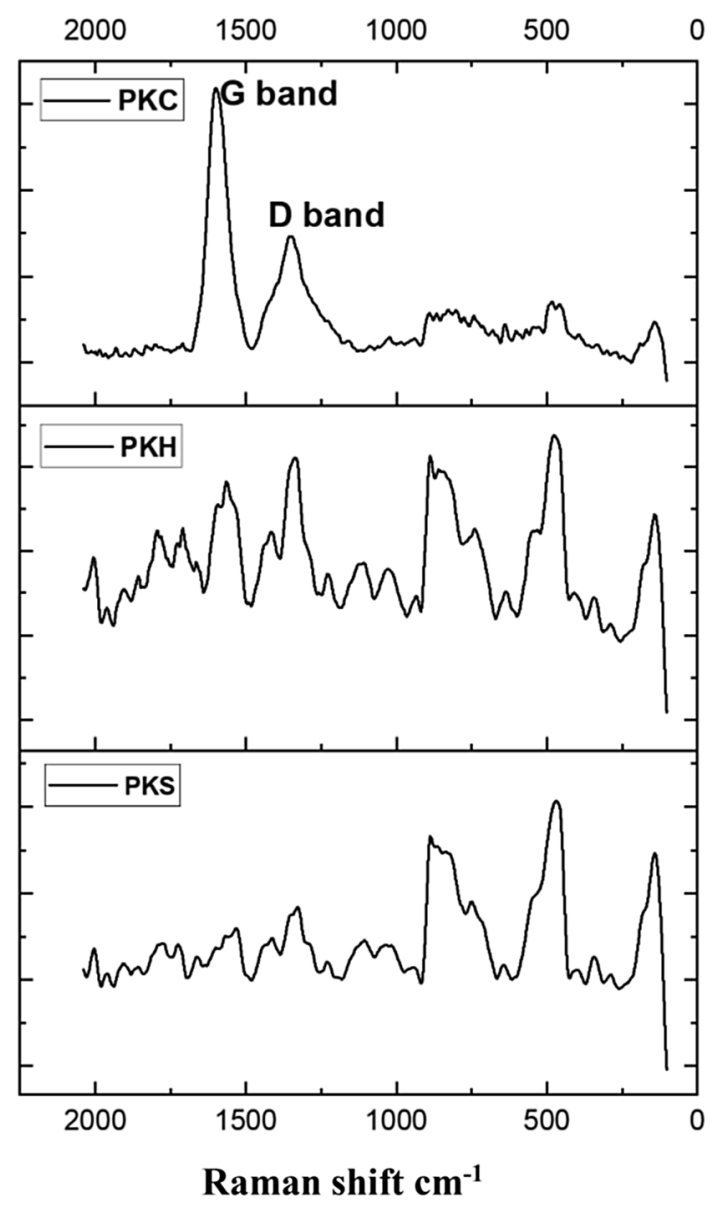

Fig. 4 Time-gated Raman spectra of dried palm kernel shells (PKS), hydrochar $(\mathrm{PKH})$ and hydrochar-derived adsorbent (PKC) peaks decrease during HTC and activation. The peaks around $1000 \mathrm{~cm}^{-1}$ can be attributed to the cellulose and hemicellulose components in the spectra of PKS and PKH. Decrease in intensity of these peaks is in correlation with the TGA results, which indicated the loss of the hemicellulosic and cellulosic components in the activation temperature range $\left(\sim 400{ }^{\circ} \mathrm{C}\right)$. Dried palm kernel shells (PKS) and hydrochar $(\mathrm{PKH})$ show also spectral features in the region of C-O stretch in cellulose and hemicellulose $\left(1056 \mathrm{~cm}^{-1}\right)$ and crystalline cellulose $\left(1098 \mathrm{~cm}^{-1}\right)$ [41]. This ties with the FTIR results, where we observed a loss of the $\mathrm{C}-\mathrm{O}$ groups after activation. We also observe prominent peaks in the Raman spectra of PKS and PKH below $900 \mathrm{~cm}^{-1}$ which are greatly reduced in the PKC spectrum. These peaks can be associated with hydrogen bonded to aromatic carbons [42].

Fig. 5 shows the XRD diffractogram of PKC. It is directly visible from the diffractogram, that the material is not wellstructured crystalline material. Similar diffractograms are typical for biowaste-derived carbons. The broad peaks visible at $2 \theta 27^{\circ}$ and at around $50^{\circ}$ are related to the disordered graphite-like structures [43, 44], that were also observed in Raman spectra. The feature visible at around $2 \theta 15^{\circ}$ could be related to graphite oxide $[45,46]$. The presence of graphite oxide in material supports the information found in FTIR analysis, namely observation of various oxygen-containing functional groups.

\section{DCF adsorption experiments}

The pHpzc of the hydrochar-derived adsorbent (PKC) was determined to be 5.7 using the $\mathrm{pH}$ drift method [47]. The $\mathrm{pKa}$ of diclofenac is $\sim 4.2$ [19]. When the $\mathrm{pH}$ of the solution is equivalent to the pKa, $50 \%$ of DCF is in protonated and $50 \%$ is in deprotonated form. When $\mathrm{pH}$ of the solution

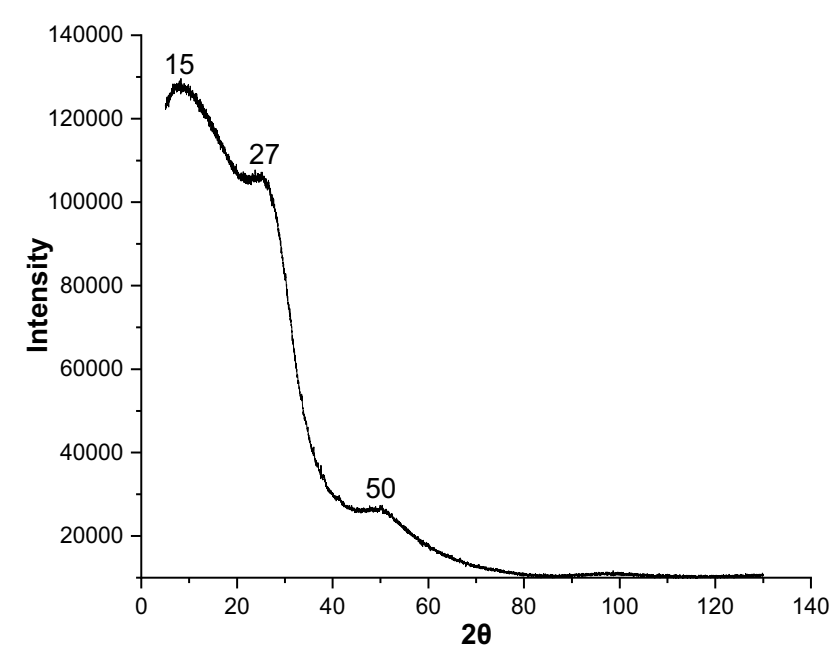

Fig. 5 XRD diffractogram of PKC 
decreases, the protonated form prevails. At the $\mathrm{pH} 2$, DCF is mainly in protonated form while the adsorbent surface is positively charged. After $\mathrm{pH}$ increases above $\mathrm{pHpzc}$ of the adsorbent, larger part of DCF is in deprotonated form and adsorbent has a negative charge. The lower $\mathrm{pH}(\mathrm{pH} 2)$ was selected for the experiments to avoid the repulsion between the adsorbate and the adsorbent surface. Furthermore, earlier studies indicate $\mathrm{pH} 2$ as optimal $\mathrm{pH}$ for diclofenac adsorption [19].

The effect of adsorbent amount in DCF removal was studied using $0.25,0.5,1.0$ and $1.5 \mathrm{~g}$ of hydrochar-derived adsorbent (PKC). The results are presented in Fig. 6a. The adsorption of DCF on PKC after $90 \mathrm{~min}$ in presence of $0.25 \mathrm{~g}$ and $1.5 \mathrm{~g}$ of adsorbent was $0.214 \mathrm{mg} \mathrm{g}^{-1}$ and $0.376 \mathrm{mg} \mathrm{g}^{-1}$, respectively. The adsorption capacity of PKC increased with increasing adsorbent mass, which is due to availability of higher number of surface sites for adsorption. Figure 5a displays that the removal of DCF increases with increasing adsorbent mass. However, when the mass of adsorbent is taken into account when calculating the amount of DCF adsorbed at a given time, the difference is not anymore equally large, which is visible in Fig. 6b. About $43 \%$ of DCF is removed during $90 \mathrm{~min}$ using $1.5 \mathrm{~g}$ of adsorbent compared to $5 \%$ removal achieved with $0.25 \mathrm{~g}$ of adsorbent. Usually, adsorption capacity and efficiency are linked to contact time and thus adsorption increases with increasing contact time until the adsorption-desorption process reaches the equilibrium. Based on the results, an amount of $1.5 \mathrm{~g}$ of adsorbent was selected for further experiments. An increase in the concentration of DCF increases the DCF removal percentage from about $75 \%$ removal at $5 \mathrm{ppm}$ to maximum removal of about $95 \%$ with 50 ppm of DCF solution (Fig. 6c).

Adsorption kinetics of DCF was examined by fitting two kinetic models to the data (Fig. 7). Compared to pseudofirst-order (PFO) model, pseudo-second-order (PSO) kinetic model explained better the experimental data with the correlation coefficients $\left(\mathrm{R}^{2}\right)$ superior than 0.93 for all the studied adsorbent amounts (Table 1). The theoretical values of adsorption quantity at equilibrium $\left(\mathrm{Q}_{\mathrm{e}, \mathrm{cal}}\left(\mathrm{mgg}^{-1}\right)\right)$ determined from PSO model were consistent with the experimental value $\left(\mathrm{Q}_{\mathrm{e}, \mathrm{exp}}\left(\mathrm{mgg}^{-1}\right)\right)$ (see Table 1$)$. The highest equilibrium adsorption capacity was observed for $1.5 \mathrm{~g}$ of adsorbent for the removal of DCF. The increase in adsorbent mass accelerated the adsorption of DCF onto adsorbent, which was shown by the increase of second-order rate constants $\left(\mathrm{K}_{2}\right)$ from 0.311 to $0.869 \mathrm{gm} \mathrm{gmin}^{-1}$.

To investigate the DCF adsorption further, Langmuir and Freundlich adsorption models were used to fit the equilibrium data. As seen in Table 2 and Fig. 8, the Langmuir model fits reasonably well with the experimental data with a correlation coefficient of $\mathrm{R}^{2}>0.98$. This means that the adsorption of DCF occurs as monolayers onto homogeneously dispersed adsorption sites on the adsorbent
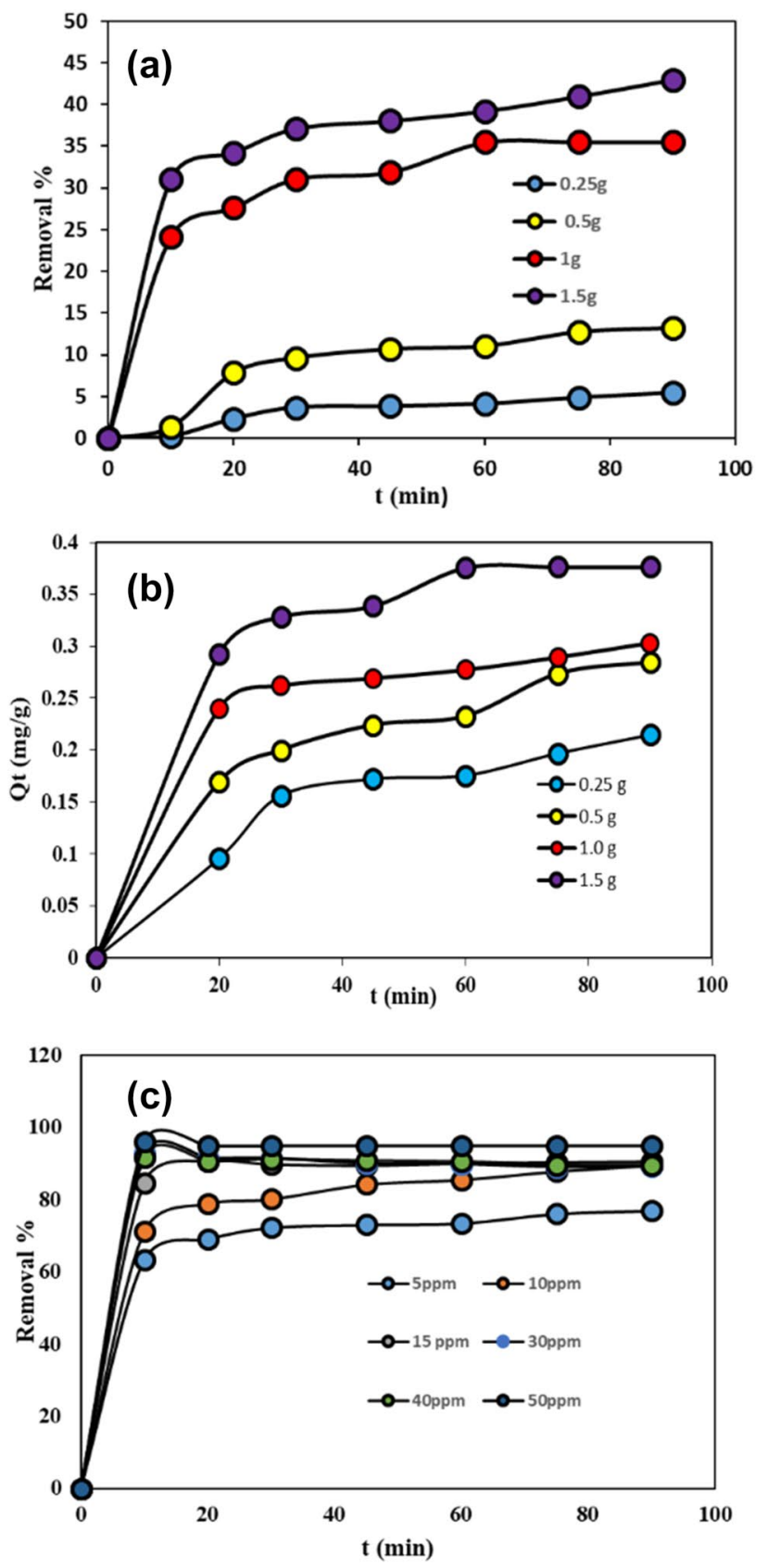

Fig. 6 a Effect of adsorbent mass and contact time on the removal efficiency of DCF. $\mathbf{b}$ Amount of adsorbed DCF at given contact times for different masses of the adsorbent (DCF concentration was 10 $\left.\mathrm{mgL}^{-1}\right)$. $\mathbf{c}$ Effect of DCF concentration on the removal of DCF at $\mathrm{pH}$ 2 (Total liquid volume $100 \mathrm{~mL}$; experiments were carried out at room temperature)

surface with absence of interaction between the adsorbed DCF molecules. The maximum amount of DCF adsorbed was $13.16 \mathrm{mg} \mathrm{g}^{-1}$ at $25^{\circ} \mathrm{C}$. Freundlich model did not fit equally well with the data based on smaller correlation coefficient $\left(R^{2}: 0.95\right)$. The value of the Freundlich constant 
Fig. 7 Fitting of kinetic data of DCF adsorption with (a) PFO kinetic model and (b) PSO model. (The models are fitted with different mass of the adsorbent. The initial concentration of DCF was $10 \mathrm{mgL}^{-1}$, temperature was $25^{\circ} \mathrm{C}$ and total volume $100 \mathrm{~mL}$.)
Table 1 Kinetic parameters of DCF adsorption onto hydrocharderived adsorbent at $25^{\circ} \mathrm{C}$ and $10 \mathrm{mgL}^{-1}$
Table 2 Langmuir and Freundlich parameters for DCF adsorption
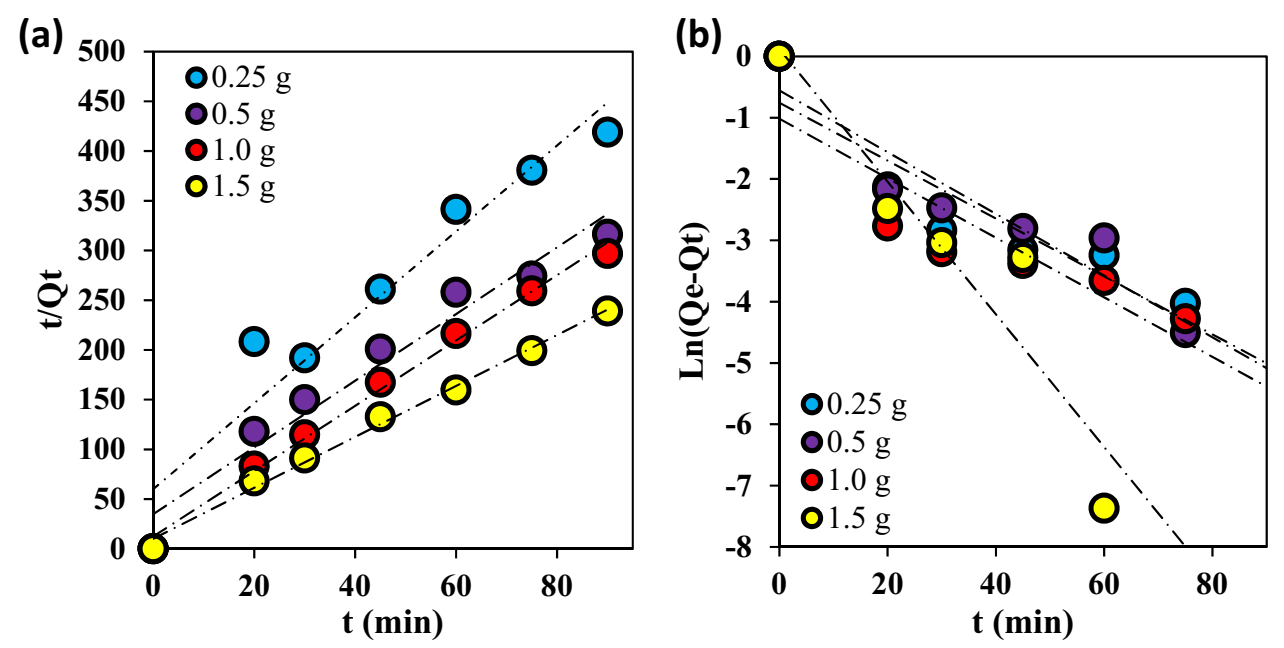

\begin{tabular}{|c|c|c|c|c|c|c|c|}
\hline \multirow{2}{*}{$\begin{array}{l}\text { Adsorbent } \\
\text { mass (g) }\end{array}$} & \multirow{2}{*}{$\mathrm{Q}_{\mathrm{e}, \exp }\left(\mathrm{mgg}^{-1}\right)$} & \multicolumn{3}{|c|}{ Pseudo-first-order (PFO) } & \multicolumn{3}{|c|}{ Pseudo-second-order (PSO) } \\
\hline & & $\mathrm{Q}_{\mathrm{e}, \mathrm{cal}}\left(\mathrm{mgg}^{-1}\right)$ & $\mathrm{K}_{1}\left(\min ^{-1}\right)$ & $\mathrm{R}^{2}$ & $\mathrm{Q}_{\mathrm{e}, \mathrm{cal}}\left(\mathrm{mgg}^{-1}\right)$ & $\mathrm{K}_{2}\left(\right.$ gmg. $\left.\min ^{-1}\right)$ & $\mathrm{R}^{2}$ \\
\hline 0.25 & 0.214 & 0.470 & 0.108 & 0.850 & 0.231 & 0.311 & 0.930 \\
\hline 0.5 & 0.284 & 0.951 & 1.278 & 0.883 & 0.298 & 0.322 & 0.958 \\
\hline 1.0 & 0.303 & 0.953 & 2.340 & 0.785 & 0.304 & 0.646 & 0.993 \\
\hline 1.5 & 0.376 & 0.898 & 0.274 & 0.880 & 0.391 & 0.869 & 0.993 \\
\hline
\end{tabular}

\begin{tabular}{lllllllll}
\hline Langmuir & & & & & Freundlich & \\
\cline { 1 - 1 } & & $\mathrm{K}_{\mathrm{L}}\left(\mathrm{Lmg}^{-1}\right)$ & $\mathrm{R}_{\mathrm{L}}$ & $\mathrm{R}^{2}$ & & $\mathrm{~K}_{\mathrm{F}}(\mathrm{mg} / \mathrm{g})(\mathrm{L} / \mathrm{mg})^{1 / \mathrm{n}}$ & $\mathrm{n}$ & $\mathrm{R}^{2}$ \\
\hline 13.16 & 0.042 & 0.320 & 0.980 & & 3.04 & 1.825 & 0.951 \\
\hline
\end{tabular}

Fig. 8 Fitting of the experimental DCF adsorption data against (a) Langmuir adsorption model and (b) Freundlich model. (The initial concentration used in the experiment was varied between 0 and $50 \mathrm{mgL}^{-1}$, mass of adsorbent was $1.5 \mathrm{~g}$, contact time 90 min, $\mathrm{pH}=2.0$ and temperature was $25^{\circ} \mathrm{C}$ )
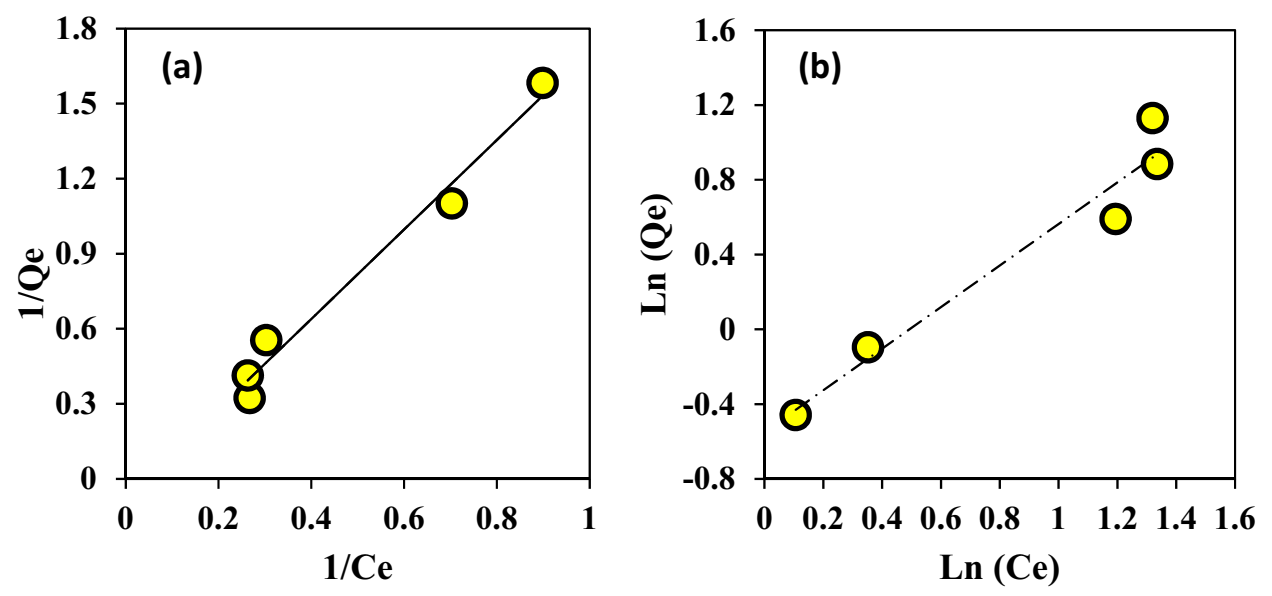

$\mathrm{n}$ is larger than 1 ( $\mathrm{n}: 1.825)$, which points out the favourable adsorption conditions.

A comparison between the maximum adsorption capacity of the adsorbent prepared in this work and the values reported earlier for physically and chemically activated carbons are presented in Table 3 . It can be observed that
PKC (13.16 $\mathrm{mgg}^{-1}$ ) has very good adsorption capacity in DCF adsorption compared to other adsorbents derived from lignocellulosic materials and activated especially by physical means. Higher adsorption capacities are achieved using $\mathrm{ZnCl}_{2}$ and $\mathrm{K}_{2} \mathrm{CO}_{3}$ as chemical activating agents. The 
Table 3 Comparison of the maximum adsorption capacity of DCF onto different adsorbents in this study and reference studies

\begin{tabular}{|c|c|c|c|c|c|c|c|}
\hline \multirow[t]{2}{*}{ Adsorbent } & \multicolumn{4}{|c|}{ Adsorption conditions } & \multirow[t]{2}{*}{$\mathrm{S}_{\mathrm{BET}}\left(\mathrm{m}^{2} \mathrm{~g}^{-1}\right)$} & \multirow[t]{2}{*}{$\mathrm{Q}_{\max }\left(\mathrm{mgg}^{-1}\right)$} & \multirow[t]{2}{*}{ Refs. } \\
\hline & $\mathrm{pH}$ & $\mathrm{C}_{\mathrm{i}}\left(\mathrm{mgL}^{-1}\right)$ & $\mathrm{T}\left({ }^{\circ} \mathrm{C}\right)$ & $\mathrm{t}(\mathrm{h})$ & & & \\
\hline Hydrochar-derived adsorbent & 2.0 & $0-50$ & 25 & 1.5 & 131 & 13.16 & This work \\
\hline Orange peel activated using air & 7.0 & $15-600$ & 25 & 24 & 499 & 5.73 & [48] \\
\hline Olive stone activated by $\mathrm{H}_{2} \mathrm{SO}_{4}$ & 4.2 & $25-150$ & 23 & 3 & - & 11.0 & [49] \\
\hline Orange peel activated by $\mathrm{K}_{2} \mathrm{CO}_{3}$ & 4.5 & $10-200$ & 30 & 24 & 457 & 5.60 & {$[50]$} \\
\hline Orange peel activated by $\mathrm{CO}_{2}$ & 7.0 & $15-600$ & 25 & 24 & 301 & 1.91 & [48] \\
\hline Cyclamen persicum tubers activated by $\mathrm{ZnCl}_{2}$ & 2.0 & $20-70$ & 15 & 2 & 881 & 22.22 & {$[19]$} \\
\hline Tea waste derived carbon activated by $\mathrm{ZnCl}_{2}$ & 6.5 & $10-50$ & 30 & 6 & 865 & 62 & {$[51]$} \\
\hline Cocoa pods husks activated by $\mathrm{H}_{2} \mathrm{SO}_{4}$ & 7 & $10-30$ & 25 & 0.75 & not known & 5 & {$[52]$} \\
\hline $\begin{array}{l}\text { Cocoa shell activated carbon, microwave }+20 \% \\
\text { lime }+40 \% \mathrm{FeCl}_{3}+40 \% \mathrm{ZnCl}_{2}\end{array}$ & 7 & $10-300$ & 25 & 3.7 & 619 & 63.5 & {$[53]$} \\
\hline Potato peel waste carbon activated by $\mathrm{K}_{2} \mathrm{CO}_{3}$ & 5 & $10-100$ & 25 & 17 & 866 & 68.5 & {$[54]$} \\
\hline
\end{tabular}

adsorption times reported for other materials have mainly been significantly longer than in our case.

The adsorption mechanism between PKC and DCF is useful to understand the performance of PKC. Despite the specific surface area of the adsorbent being only about 131 $\mathrm{m}^{2} \mathrm{~g}^{-1}$, we obtained a good removal of $95 \%$ at $\mathrm{pH} 2$. At this $\mathrm{pH}$, the electrostatic interactions cannot explain the good performance of the adsorbent, since the pKa of DCF is $\sim 4.2$ (typical for weak acid) and at the $\mathrm{pH}$ of the experiment, DCF is mainly present in protonated form while the adsorbent is positively charged. The result indicates that the surface functional groups played a major role in the adsorption of DCF onto PKC. DCF molecule contains three non-polar structures-two aromatic rings and hydrocarbon chain. Diarylamine and carboxyl acid groups improve the DCF solubility in water. Diarylamine and carboxylic acid groups can form strong hydrogen bonds, while non-polar groups can create Van der Waals bonding with other non-polar groups. The aromatic rings can also create $\pi-\pi$ interaction via aromatic stacking. The FTIR spectrum of PKC showed the presence of phenolic groups that improve the bonding between DCF and the adsorbent [55-57]. The interaction via aromatic $\pi-\pi$ stacking and hydrogen bonding between -OH groups of phenol and carboxylic acid groups of DCF are probably the main cause for good removal at acidic $\mathrm{pH}$.

\section{Regeneration and reusability}

Spent PKC was regenerated after DCF adsorption according to the protocol proposed by Zbair et al. [58, 59]. The results presented in Fig. 9 show, that PKC has a very good performance after five cycles of adsorption and regeneration. Furthermore, the removal efficiency remains steady without any significant loss in its ability to adsorb DCF. This shows that the developed adsorbent can be used several times before

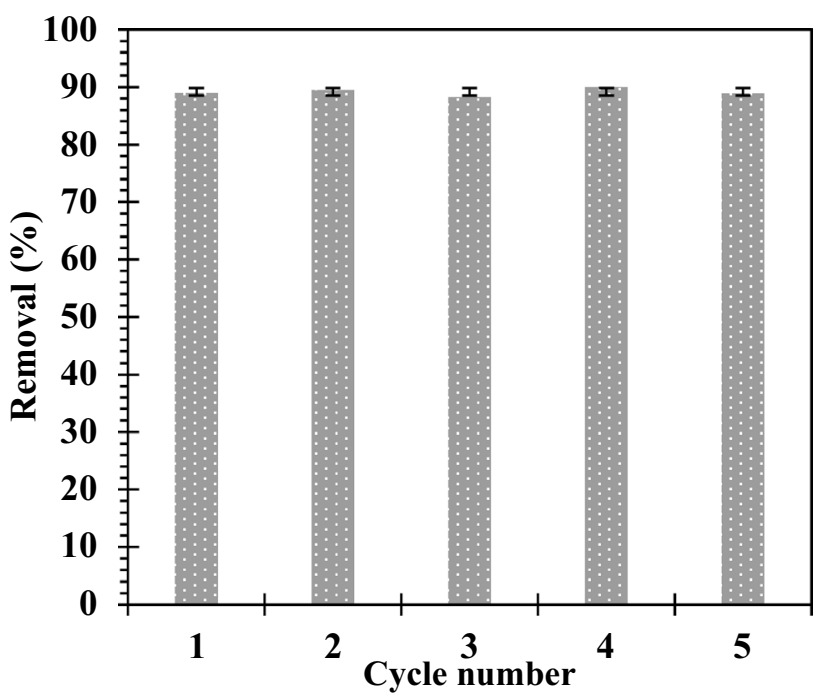

Fig. 9 Reusability of PKC adsorbent after cycles of adsorption and regeneration. (Adsorption experiments were carried out with $15 \mathrm{mg}$ ${ }^{-1} \mathrm{DCF}, 1.5 \mathrm{~g}$ of PKC, $100 \mathrm{~mL}$ total volume and $25^{\circ} \mathrm{C}$ temperature. Regeneration was done using $20 \mathrm{~mL}$ 95\% ethanol.)

it loses its adsorption capacity, which is important in the practical use of the material.

\section{Conclusions}

An efficient adsorbent for diclofenac removal from water was successfully developed through hydrothermal carbonization and activation under $\mathrm{N}_{2}$ flow. The prepared adsorbent was mesoporous and it had specific surface area of 131 $\mathrm{m}^{2} \mathrm{~g}^{-1}$. Based on FTIR analysis, the hydrochar surface was rich in oxygen containing functional groups, while their quantity and quality decreased after activation. Activation increased the amount of graphene and graphite structures 
in the material while cellulose and hemicellulose structures were removed. Maximum adsorption capacity of 13.16 $\mathrm{mgg}^{-1}$ for diclofenac was achieved, which is better than capacities reported in several previous works. The adsorption equilibrium followed the Langmuir model meaning that diclofenac adsorption occurs as monolayers on homogenously dispersed adsorption sites. The adsorption kinetics was explained better by pseudo-second-order kinetic model. The repeated regeneration experiments showed that the material kept high adsorption capacity even after five cycles. This study demonstrates that hydrothermal carbonization can be used as a basic process for production of an efficient hydrochar-derived adsorbent that has a good potential in the low-cost water purification applications.

Funding This work is funded by I4FUTURE doctoral program that has received funding from the EU H2020 under Marie Sklodowska Curie Grant Agreement No. 713606.

\section{Compliance with ethical standards}

Conflict of interest The authors declare that they have no conflict of interest.

Open Access This article is licensed under a Creative Commons Attribution 4.0 International License, which permits use, sharing, adaptation, distribution and reproduction in any medium or format, as long as you give appropriate credit to the original author(s) and the source, provide a link to the Creative Commons licence, and indicate if changes were made. The images or other third party material in this article are included in the article's Creative Commons licence, unless indicated otherwise in a credit line to the material. If material is not included in the article's Creative Commons licence and your intended use is not permitted by statutory regulation or exceeds the permitted use, you will need to obtain permission directly from the copyright holder. To view a copy of this licence, visit http://creativecommons.org/licenses/by/4.0/.

\section{References}

1. Wang L, Chang Y, Li A (2019) Hydrothermal carbonization for energy-efficient processing of sewage sludge: a review. Renew Sustain Energy Rev 108:423-440

2. Han L, Sun H, Ro K, Sun K, Libra J, Xing B (2017) Removal of antimony (III) and cadmium (II) from aqueous solution using animal manure-derived hydrochars and pyrochars. Biores Technol 234:77-85

3. Sharma R, Jasrotia K, Singh N, Ghosh P, Srivastava S, Sharma N, Singh J, Kanwar R, Kumar A (2019) A comprehensive review on hydrothermal carbonization of biomass and its applications. Chem Afr 3(1):1-19

4. Sun Y, Gao B, Yao Y, Fang J, Zhang M, Zhou Y, Chen H, Yang L (2014) Effects of feedstock type, production method, and pyrolysis temperature on biochar and hydrochar properties. Chem Eng J 240:574-578

5. Taskin E, de Castro Bueno C, Allegretta I, Terzano R, Rosa A, Loffredo E (2019) Multianalytical characterization of biochar and hydrochar produced from waste biomasses for environmental and agricultural applications. Chemosphere 233:422-430

6. Berge N, Li L, Flora J, Ro K (2015) Assessing the environmental impact of energy production from hydrochar generated via hydrothermal carbonization of food wastes. Waste Manage 43:203-217

7. Wang L, Guo Y, Zhu Y, Li Y, Qu Y, Rong C, Ma X, Wang Z (2010) A new route for preparation of hydrochars from rice husk. Biores Technol 101(24):9807-9810

8. Fang J, Zhan L, Ok Y, Gao B (2018) Minireview of potential applications of hydrochar derived from hydrothermal carbonization of biomass. J Ind Eng Chem 57:15-21

9. Guo N, Li M, Sun X, Wang F, Yang R (2017) Enzymatic hydrolysis lignin derived hierarchical porous carbon for supercapacitors in ionic liquids with high power and energy densities. Green Chem 19(11):2595-2602

10. Guo S, Dong X, Zhu C, Han Y, Ma F, Wu T (2017) Pyrolysis behaviors and thermodynamics properties of hydrochar from bamboo (Phyllostachys heterocycla cv. pubescens) shoot shell. Bioresour Technol 233:92-98

11. Kambo H, Dutta A (2015) A comparative review of biochar and hydrochar in terms of production, physico-chemical properties and applications. Renew Sustain Energy Rev 45:359-378

12. Puccini M, Stefanelli E, Tasca AL, Vitolo S (2018) Pollutant removal from gaseous and aqueous phases using hydrocharbased activated carbon. Chem Eng Trans 67:637-642

13. Yang D, Li Z, Liu M, Zhang X, Chen Y, Xue H, Ye E, Luque $\mathrm{R}$ (2019) Biomass-derived carbonaceous materials: recent progress in synthetic approaches, advantages, and applications. ACS Sustain Chem Eng 7(5):4564-4585

14. Herawan S, Hadi M, Ayob M, Putra A (2013) Characterization of activated carbons from oil-palm shell by $\mathrm{CO}_{2}$ activation with no holding carbonization temperature. Sci World J 2013:1-6

15. Issabayeva G, Aroua M, Sulaiman N (2006) Removal of lead from aqueous solutions on palm shell activated carbon. Biores Technol 97(18):2350-2355

16. Lua A, Jia Q (2009) Adsorption of phenol by oil-palm-shell activated carbons in a fixed bed. Chem Eng J 150(2-3):455-461

17. Onundi Y, Mamun A, Khatib M, Ahmed Y (2010) Adsorption of copper, nickel and lead ions from synthetic semiconductor industrial wastewater by palm shell activated carbon. Int J Environ Sci Technol 7(4):751-758

18. Tan I, Ahmad A, Hameed B (2008) Adsorption of basic dye using activated carbon prepared from oil palm shell: batch and fixed bed studies. Desalination 225(1-3):13-28

19. Jodeh S, Abdelwahab F, Jaradat N, Warad I, Jodeh W (2016) Adsorption of diclofenac from aqueous solution using Cyclamen persicum tubers based activated carbon (CTAC). J Assoc Arab Univ Basic Appl Sci 20(1):32-38

20. Joss A, Keller E, Alder A, Göbel A, McArdell C, Ternes T, Siegrist H (2005) Removal of pharmaceuticals and fragrances in biological wastewater treatment. Water Res 39(14):3139-3152

21. Landry K, Boyer $\mathrm{T}$ (2013) Diclofenac removal in urine using strong-base anion exchange polymer resins. Water Res 47(17):6432-6444

22. Lienert J, Güdel K, Escher B (2007) Screening method for ecotoxicological hazard assessment of 42 pharmaceuticals considering human metabolism and excretory routes. Environ Sci Technol 41(12):4471-4478

23. Thanhmingliana T, Tiwari D (2015) Efficient use of hybrid materials in the remediation of aquatic environment contaminated with micro-pollutant diclofenac sodium. Chem Eng J 263:364-373

24. Mehinto A, Hill E, Tyler C (2010) Uptake and biological effects of environmentally relevant concentrations of the nonsteroidal anti-inflammatory pharmaceutical diclofenac in rainbow trout (Oncorhynchus mykiss). Environ Sci Technol 44(6):2176-2182 
25. Vergili I (2013) Application of nanofiltration for the removal of carbamazepine, diclofenac and ibuprofen from drinking water sources. J Environ Manag 127:177-187

26. Antero R, Alves A, Ferreira Sales P, de Oliveira S, Ojala S, Brum S (2019) A new approach to obtain mesoporous-activated carbon via hydrothermal carbonization of Brazilian Cerrado biomass combined with physical activation for bisphenol-a removal. Chem Eng Commun 206(11):1498-1514

27. Langmuir I (1916) The constitution and fundamental properties of solids and liquids. Part I Solids. J Am Chem Soc 252:2221-95. https://doi.org/10.1021/ja02268a002

28. Freundlich H (1906) Über die adsorption in lösungen. Zeitschrift Für Phys Chemie 57A:385

29. Lagergren S, B. S (1898) Zur theorie der sogenannten adsorption geloester stoffe. Veternskapsakad Handl. 24:1-39

30. Liu Y (2008) New insights into pseudo-second-order kinetic equation for adsorption. Coll Surf A Physicochem Eng Asp 320:275-8

31. Smith A, Singh S, Ross A (2016) Fate of inorganic material during hydrothermal carbonisation of biomass: influence of feedstock on combustion behaviour of hydrochar. Fuel 169:135-145

32. Hamza U, Nasri N, Amin N, Mohammed J, Zain H (2015) Characteristics of oil palm shell biochar and activated carbon prepared at different carbonization times. Desalination Water Treat 57(17):7999-8006

33. Bazan A, Nowicki P, Półrolniczak P, Pietrzak R (2016) Thermal analysis of activated carbon obtained from residue after supercritical extraction of hops. J Therm Anal Calorim 125(3):1199-1204

34. Zbair M, Bottlinger M, Ainassaari K, Ojala S, Stein O, Keiski RL et al (2018) Hydrothermal carbonization of argan nut shell: functional mesoporous carbon with excellent performance in the adsorption of bisphenol A and diuron. Waste Biomass Valoriz. https://doi.org/10.1007/s12649-018-00554-0

35. Ulfah M, Raharjo S, Hastuti P, Darmadji P (2016) The potential of palm kernel shell activated carbon as an adsorbent for $\beta$-carotene recovery from crude palm oil. AIP Conf Proc 1755:130016

36. Siipola V, Tamminen T, Källi A, Kupila R, Romar H, Rasa K, Keskinen R, Hyväluoma J, Hannula M, Wikberg H (2018) Effects of biomass type, carbonization process, and activation method on the properties of bio-based activated carbons. BioResources 13:3

37. Hidayu A, Sukor M, Mohammad N, Elham O, Azri N, Azhar M, Jalil M (2019) Preparation of activated carbon from palm kernel shell by chemical activation and its application for $\beta$-carotene adsorption in crude palm oil. J Phys Conf Ser 1349:012103

38. Pal T, Paul S, Sa B (2011) Polymethylmethacrylate coated alginate matrix microcapsules for controlled release of diclofenac sodium. Pharmacol Pharm 02(02):56-66

39. Nicholas A, Hussein M, Zainal Z, Khadiran T (2018) Palm kernel shell activated carbon as an inorganic framework for shapestabilized phase change material. Nanomaterials 8(9):689

40. Majdoub M, Essamlali Y, Amadine O, Ganetri I, Zahouily M (2019) Organophilic graphene nanosheets as a promising nanofiller for bio-based polyurethane nanocomposites: investigation of the thermal, barrier and mechanical properties. New J Chem 43(39): 15659-15672

41. Nanda S, Mohanty P, Pant K, Naik S, Kozinski J, Dalai A (2012) Characterization of North American lignocellulosic biomass and biochars in terms of their candidacy for alternate renewable fuels. BioEnergy Res 6(2):663-677

42. Pardanaud C, Cartry G, Lajaunie L, Arenal R, Buijnsters J (2019) Investigating the possible origin of Raman bands in defective sp2/ sp3 carbons below $900 \mathrm{~cm}-1$ : phonon density of states or double resonance mechanism at play? C J Carbon Res 5(4):79

43. RRUFF (2020). An integrated database for Raman, X-ray diffraction and chemistry data for minerals. Available online at: www. ffuff.info (retrieved on 24.11.2020)
44. Ramesh T, Rajalakshmi N, Kaveripatnam S, Dhathathreyan (2017) Synthesis and characterization of activated carbon from jute fibers for hydrogen storage. Renew Energy Environ Sustain 2:4. https:// doi.org/10.1051/rees/2017001

45. Johra FT, Lee J-W, Jung W-G (2014) Facile and safe graphene preparation on solution based platform. J Ind Eng Chem 20:28832887. https://doi.org/10.1016/j.jiec.2013.11.022

46. Zhang K, Zhang Y, Wang S (2014) Enhancing thermoelectric properties of organic composites through hierarchical nanostructures. Sci Rep. https://doi.org/10.1038/srep03448

47. Yang Y, Chun Y, Sheng G, Huang M (2004) pH-Dependence of pesticide adsorption by wheat-residue-derived black carbon. Langmuir 20(16):6736-6741

48. Fernandez ME, Ledesma B, Román S, Bonelli PR, Cukierman AL (2015) Development and characterization of activated hydrochars from orange peels as potential adsorbents for emerging organic contaminants. Bioresour Technol 183:221-228. https://doi.org/ 10.1016/j.biortech.2015.02.035

49. Larous S, Meniai AH (2016) Adsorption of Diclofenac from aqueous solution using activated carbon prepared from olive stones. Int J Hydrogen Energy 41:10380-10390. https://doi.org/10.1016/j. ijhydene.2016.01.096

50. Tomul F, Arslan Y, Başoğlu FT, Babuçcuoğlu Y, Tran HN (2019) Efficient removal of anti-inflammatory from solution by Fe-containing activated carbon: adsorption kinetics, isotherms, and thermodynamics. J Environ Manag 238:296-306. https://doi.org/10. 1016/j.jenvman.2019.02.088

51. Malhotra M, Suresh S, Garg A (2018) Tea waste derived activated carbon for the adsorption of sodium diclofenac from wastewater: adsorbent characteristics, adsorption isotherms, kinetics, and thermodynamics. Environ Sci Pollut Res 25(32):32210-32220

52. de Luna M, Murniati BW, Rivera K, Arazo R (2017) Removal of sodium diclofenac from aqueous solution by adsorbents derived from cocoa pod husks. J Environ Chem Eng 5(2):1465-1474

53. Saucier C, Adebayo M, Lima E, Cataluña R, Thue P, Prola L, Puchana-Rosero M, Machado F, Pavan F, Dotto G (2015) Microwave-assisted activated carbon from cocoa shell as adsorbent for removal of sodium diclofenac and nimesulide from aqueous effluents. J Hazard Mater 289:18-27

54. Bernardo M, Rodrigues S, Lapa N, Matos I, Lemos F, Batista M, Carvalho A, Fonseca I (2016) High efficacy on diclofenac removal by activated carbon produced from potato peel waste. Int J Environ Sci Technol 13(8):1989-2000

55. Mao N, Huang L, Shuai Q (2019) Facile synthesis of porous carbon for the removal of diclofenac sodium from water. ACS Omega 4(12):15051-15060

56. Schames J, Henchman R, Siegel J, Sotriffer C, Ni H, McCammon J (2004) Discovery of a novel binding trench in HIV integrase. J Med Chem 47(8):1879-1881

57. Chen W, Duan L, Zhu D (2007) Adsorption of polar and nonpolar organic chemicals to carbon nanotubes. Environ Sci Technol 41(24):8295-8300

58. Zbair M, Ainassaari K, El Assal Z, Ojala S, El Ouahedy N, Keiski RL et al (2018) Steam activation of waste biomass: highly microporous carbon, optimization of bisphenol A, and diuron adsorption by response surface methodology. Environ Sci Pollut Res 25:35657-35671. https://doi.org/10.1007/s11356-018-3455-3

59. Zbair M, Ainassaari K, Drif A, Ojala S, Bottlinger M, Pirilä M et al (2018) Toward new benchmark adsorbents: preparation and characterization of activated carbon from argan nut shell for bisphenol a removal. Environ Sci Pollut Res. https://doi.org/10.1007/ s11356-017-0634-6

Publisher's Note Springer Nature remains neutral with regard to jurisdictional claims in published maps and institutional affiliations. 


\section{Authors and Affiliations}

\section{Velma Beri Kimbi Yaah ${ }^{1} \cdot{\text { Mohamed } \text { Zbair }^{2} \text { · Sérgio Botelho de Oliveira }}^{3} \cdot$ Satu Ojala ${ }^{1}$ (]}

$\triangle$ Satu Ojala

satu.ojala@oulu.fi

1 Environmental and Chemical Engineering Research Unit, Faculty of Technology, University of Oulu, Oulu, Finland
2 Laboratory of Catalysis and Corrosion of Materials (LCCM), Faculty of Sciences, University of Chouaib Doukkali, El Jadida, Morocco

3 Federal Institute of Goiás - IFG, Goiania, Brazil 